\title{
Saffron- An Ancient Culinary Spice
}

\author{
Nida Tabassum Khan* and Namra Jameel \\ Department of Biotechnology, Faculty of Life Sciences and Informatics, Balochistan University of Information Technology \\ Engineering and Management Sciences, (BUITEMS), Quetta, Pakistan
}

*Corresponding author: Nida Tabassum Khan, Department of Biotechnology, Faculty of Life Sciences and Informatics, Balochistan University of Information Technology Engineering and Management Sciences, (BUITEMS), Quetta, Pakistan

\begin{tabular}{|c|c|}
\hline ARTICLE INFO & ABSTRACT \\
\hline Received: 蔧 June 30, 2020 & Saffron is an expensive ancient culinary spice with a sturdy fragrance and yellow- \\
\hline Published: 幽 July 09, 2020 & $\begin{array}{l}\text { ish golden color that is mostly used in cooking. It is also enriched source of vitamins, } \\
\text { essential minerals, and many nonvolatile components as well that possess antioxidants }\end{array}$ \\
\hline $\begin{array}{l}\text { Citation: Saffron- An Ancient Culinary } \\
\text { Spice. Nida Tabassum Khan, Namra Jameel. } \\
\text { Biomed J Sci \& Tech Res 28(5)-2020. BJSTR. } \\
\text { MS.ID.004703. }\end{array}$ & $\begin{array}{l}\text { as infertility in males, depression, mental illness, oxidative stress and other gynecologi- } \\
\text { cal problems in females., erectile dysfunction, and infections Saffron is an and expensive } \\
\text { herb. } \\
\text { Keywords: Oxidative Stress; Erectile Dysfunction; Premenstrual Syndrome; Crocetin; } \\
\text { Alzheimer }\end{array}$ \\
\hline
\end{tabular}

\section{Introduction}

Saffron is basically dried thread like structures derived from the style and stigma of the perennial flower Crocus sativus [1]. It is recognized in the culinary world as an expensive flavoring spice because of its laborious manual cultivation and harvesting referred to as Red Gold [2]. Iran, India, Spain and Greece are the well-recognized producers of saffron [3]. Besides being used in culinary it is also known to possess medicinal potencies such as given to patients suffering from depression, alopecia, premenstrual syndromes, premature ejaculation, infertility and Alzheimer disease $[4,5]$. In addition, extracts of saffron are used in textile dying and manufacturing fragrances [6].

\section{Nutritional Contents}

Saffron contains numerous essential volatile oils such as geraniol, cineole, pinene, linalool, borneol, limonene, p-cymene, phenethenol, terpinen-4-oil, etc [7-9] and non-volatile components such as crocin, lycopene, zeaxanthin and carotenes which is responsible for its yellowish golden color and flavor [10]. In addition to that, saffron provides numerous essential minerals and vitamins including manganese, magnesium, potassium, zinc, calcium, copper iron, selenium etc and vitamin C/A, riboflavin, niacin and folic acid respectively $[11,12]$.

\section{Health Benefits of Saffron}

Saffron has been reported to aid in the treatment of several diseases and clinical symptoms some of which are enlisted below: a) Depression: Saffron is reported to be an effective antidepressant because it contains crocin, a well-known chemical compound which alleviates depression associated symptoms at a much faster rate [13]

b) Premenstrual Syndrome: Saffron is known to reduce menstrual pain during the female's fertility cycle [14]

c) Lowers Blood Sugar Level: It has been reported that intake of saffron can prevent blood sugar elevation [15].

d) Asthma: Patients with allergic asthma is mostly treated with saffron containing herbal tea however the exact mechanism or agent responsible for this effect is still a mystery [16].

e) Muscle Performance: Recent studies reported that a compound namely crocetin in saffron is responsible for reducing muscle sores and fatigue to improve muscle performance such as during exercise or athletics [17].

f) Infertility: Saffron is also reported to treat men with erectile dysfunction without altering the viability of the semen [18].

g) Antioxidants: Saffron is known to possess plants derived antioxidant compounds including crocetin, crocin, kaempferol, picrocrocin, safranal etc that aids in fighting against oxidative stress [19]. 
h) Nervous System Disorders: Saffron possess antioxidant and antidepressant property therefore is known to reduce oxidative stress and inflammation in the brain tissue $[20,21]$. In addition, saffron increases brains dopamine levels without disturbing normal serotonin levels [22].

i) Obesity: Intake of saffron promotes weight loss by reducing total fat mass and waist circumference by controlling compulsive overeating and curbing appetite [23].

\section{Side Effects of Saffron}

Over consumption of saffron might have undesirable effects such as it was reported in pregnant women that increased uptake of saffron resulted in premature uterine stimulation causing bleeding [24]. Besides conditions like allergic reactions, anxiety, drowsiness, lower blood pressure, sweating, vomiting, constipation etc were also reported in some individuals $[25,26]$.

\section{Conclusion}

Saffron is commonly used as a flavoring agent in Asian and Mediterranean cuisines. But it is also known to possess antioxidants and antidepressant properties for which it is employed in the treatment of several medical conditions such as nervous system disorders and depression.

\section{References}

1. Winterhalter P, Straubinger M (2000) Saffron-renewed interest in an ancient spice. Food Reviews International 16(1): 39-59.

2. Madan CL, Kapur BM, Gupta US (1966) Saffron. Economic botany 20(4) 377-385.

3. Sampathu SR, Shivashankar S, Lewis YS, Wood AB (1984) Saffron (Crocus sativus Linn.)-Cultivation, processing, chemistry, and standardization. Critical Reviews in Food Science \& Nutrition 20(2): 123-157.

4. Bhargava V (2011) Medicinal uses and pharmacological properties of Crocus sativus Linn (Saffron). Int J Pharm Pharm Sci 3: 22-26.

5. Rios JL, Recio MC, Giner RM, Manez S (1996) An update review of saffron and its active constituents. Phytotherapy Research 10(3): 189-193.

6. Mortazavi SM, Kamali, MM, Safi S, Salehi R (2012) Saffron petals, a byproduct for dyeing of wool fibers.

7. Khayyat SA (2017) Phytochemical and antimicrobial studies of Saffron and its essential oil. Journal of Computational and Theoretical Nanoscience 14(9): 4204-4211.

8. Ahmed N, Anwar S, Al-Sokari SS, Ansari SY, Wagih ME (2016) Saffron Crocus (Crocus sativus) Oils. In Essential Oils in Food Preservation, Flavor and Safety pp. 705-713.

9. Heydari S, Haghayegh GH (2014) Extraction and microextraction techniques for the determination of compounds from saffron. Can Chem Trans 2: 221-247.
10. Cadwallader KR (2002) Flavor chemistry of saffron. ACS Symposium Series 802 16: 220-239.

11. Bolhassani A, Khavari A, Bathaie SZ (2014) Saffron and natural carotenoids: Biochemical activities and anti-tumor effects. Biochimica et Biophysica Acta (BBA)-Reviews on Cancer 1845(1): 20-30.

12. Bathaie SZ (2012) Saffron as a functional food and a nutraceutical using saffron and its constituents as the nutraceutics to protect against chronic diseases. In IV International Symposium on Saffron Biology and Technology 1200: 201-204.

13. Shafiee M, Arekhi S, Omranzadeh A, Sahebkar A (2018) Saffron in the treatment of depression, anxiety and other mental disorders: Current evidence and potential mechanisms of action. Journal of affective disorders 227: 330-337.

14. Beiranvand SP, Beiranvand NS, Moghadam ZB, Birjandi M, Azhari S, et al. (2016) The effect of Crocus sativus (saffron) on the severity of premenstrual syndrome. European Journal of Integrative Medicine 8(1): $55-61$.

15. Elgazar AF, Rezq AA, Bukhari HM (2013) Anti-hyperglycemic effect of saffron extract in alloxan-induced diabetic rats. Eur J Biol Sci 5(1): 14-22.

16. Moghaddasi MS (2010) Saffron chemicals and medicine usage. Journal of medicinal plants research 4(6): 427-430.

17. Meamarbashi A, Rajabi A (2016) Potential ergogenic effects of saffron. Journal of dietary supplements 13(5): 522-529.

18. Heydari M, Rezanezhadi JB, Delfan B, Birjandi M, Kaviani H, et al. (2008) Effect of saffron on semen parameters of infertile men.

19. Goli SAH, Mokhtari F, Rahimmalek M (2012) Phenolic compounds and antioxidant activity from saffron (Crocus sativus L.) petal. Journal of Agricultural Science 4(10): 175.

20. Khazdair MR, Boskabady MH, Hosseini M, Rezaee R, Tsatsakis AM (2015) The effects of Crocus sativus (saffron) and its constituents on nervous system: A review. Avicenna journal of phytomedicine 5(5): 376.

21. Nassiri-Asl M, Hosseinzadeh H (2015) Neuropharmacology effects of saffron (Crocus sativus) and Its active constituents. In Bioactive Nutraceuticals and Dietary Supplements in Neurological and Brain Disease Academic Press p. 29-39.

22. Kyriakoudi A, Ordoudi SA, Roldán Medina M, Tsimidou MZ (2015) Saffron, A functional spice. Austin J Nutri Food Sci 3(1): 1059.

23. Mashmoul M, Azlan A, Khazaai H, Yusof BNM, Noor SM (2013) Saffron: a natural potent antioxidant as a promising anti-obesity drug. Antioxidants 2(4): 293-308.

24. Ferrence SC, Bendersky G (2004) Therapy with saffron and the goddess at Thera. Perspectives in biology and medicine 47(2): 199-226.

25. Guldiken B, Ozkan G, Catalkaya G, Ceylan FD, Yalcinkaya IE, et al. (2018) Phytochemicals of herbs and spices: Health versus toxicological effects. Food and Chemical Toxicology 119: 37-49.

26. Schmidt M, Betti G, Hensel A (2007) Saffron in phytotherapy: pharmacology and clinical uses. Wiener Medizinische Wochenschrift 157(13-14): 315-319. 
ISSN: 2574-1241

DOI: 10.26717/BJSTR.2020.28.004703

Nida Tabassum Khan. Biomed J Sci \& Tech Res

(C) $(9)$ This work is licensed under Creative

Submission Link: https://biomedres.us/submit-manuscript.php

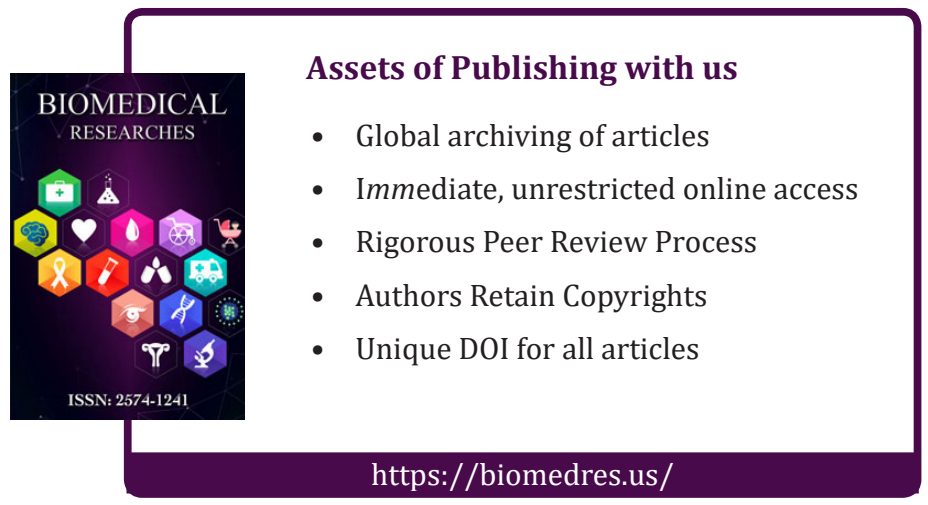

